\title{
The Assessment of Sugar Beet Half-sib Families based on some Morphophysiological Traits under Drought Stress Conditions
}

\section{Keyvan Fotouhi ${ }^{1,2 *}$, Eslam Majidi Heravan', Abazar Rajabi' ${ }^{2}$ Reza Azizinejad ${ }^{1}$}

${ }^{1}$ Department of Science and Research, Islamic Azad University, Tehran, Iran

${ }^{2}$ Sugar beet Seed Institute(SBSI), Karaj, Iran

Study Area: Karaj \& Miandoab Iran

Coordinates: $35^{\circ} 59^{\prime} \mathrm{N} ; 5^{\circ} 6^{\prime} \mathrm{E} \& 36^{\circ} 58^{\prime} \mathrm{N} ; 46^{\circ} 90^{\prime} \mathrm{E}$

Key words: Cluster analysis, Heritability, Sugar beet, Extraction coeff icient of sugar

\section{Introduction:}

ISugar beet (Beta vulgaris L.) has a high capacity for osmotic adjustment and is tolerant to drought and salinity conditions due to having a long growth period, lack of a susceptible flowering stage and deep rooting system. Drought stress is considered a major problem for successful production of field crops in the world including Iran and is known as the main factor for reduced yield in sugar beet (Ober et al., 2004). There is genetic variation for drought tolerance in sugar beet germplasm (Pidgeon et al.,
Abstract

In order to estimate heritability and relationships among traits, 43 diploid sugar beet half-sib families were evaluated in a randomised complete block design with three replications in two locations (Karaj and Miandoab) in drought stress condition. Results of combined analysis of variance showed that there was significant difference between the two locations in terms of root yield, sugaryield, white sugar yield, alkalinity, chlorophyll content, water use efficiency, specific leaf weight and leaf succulence index. There werealso signif icant differences among genotypes for all traits except potassium content, white sugar yield and specific leaf weight. The genotype by environment interaction was significant only for sodium, potassium, alkalinity and extraction coefficient of sugar. The heritability values estimated for root yield, sugar content, white sugar content, sugar yield, extraction coefficient of sugar, white sugar yield and chlorophyll content were $60.61 \%, 87.10 \%$, 90.88\%, 47.90\%, 83.91\%, 64.0\% and $81.11 \%$, respectively. The highest genetic gain belonged to root yield, extraction coefficient of sugar, chlorophyll content and sugar content, respectively. White sugar yield showed a significant positive correlation with root yield, sugar content, sugar yield, extraction coefficient of sugar, white sugar content, chlorophyll content, water use eff iciency and specific leaf weight and significant negative correlation with sodium, potassium, alkalinity and molasses sugar. Furthermore, sugar yield, molasses sugar and white sugar content explained $99 \%$ of white sugar yield variation and were identified as the most effective traits on white sugar yield. Finally, based on the results of cluster analysis, 43 sugar beet genotypes were divided into three groups with the superior genotypes being placed in the first cluster.

2006; Abdollahian et al., 2011). Rajabi et al. (2013) observed significant differences among sugar beet half-sib families in drought stress and non-stress conditions.

Presence of genetic diversity in breeding populations as the primary material for plant breeding is of special importance, a fact that makes it possible for the plant breeder to compare, group and select desirable genotypes from breeding populations. To estimate the genetic gain for a trait, it is necessary to know the correlation of that trait with the other traits and determine the nature of the 
correlation (Agrama, 1996). When the number of independent variables affecting the dependent variable is high, the extent of interdependence of the traits is limited and so the correlations alone cannot explain the relationships among the traits. When the sources of variation for yield and yield components are identif ied, it would be possible to enhance the yield potential through plant breeding and/or improved cultural practices (Board et al., 1997).

In plant breeding programs, the selection is done based on several agronomic traits among which there may be positive and significant correlations. Therefore, analyses which reduce the number of traits affecting yield without losing a lot of useful information are valuable for researchers. In this regard, it is common to use correlations among traits but there are limitations in grouping and selecting the superior genotypes. These limitations are mainly due to include various traits in the final selection of genotypes. Therefore, multivariate methods such as path and cluster analyses are able to detect the relationships among traits and facilitate the grouping and selection of the genotypes (Moghadam et al., 1994).

Fotouhi et al. (2010) studied the direct and indirect effects of different traits on root yield of sugar beet in salt stress condition and found that Sodium $(\mathrm{Na})$ had direct and negative effect and potassium $(\mathrm{K})$ had direct and positive effect on root yield with $96 \%$ of the variation of root yield being explained by $\mathrm{Na}, \mathrm{K}$, green crop cover and number of plants. Ouda Sohier (2005) introduced root yield and sugar content as the traits with the highest influence on sugar yield. Sharifi (2014) studied the correlation and path analysis of white sugar yield with some traits under irrigation regimes in sugar beet and found that sugar content, $\mathrm{Na}$, extraction coefficient of sugar and canopy temperature in the first order and leaf osmotic potential in the second order had high correlations with white sugar yield. None of these traits had the significant correlation with white sugar yield in severe stress condition. Also, their path analysis showed that in non-stress condition, sugar content, extraction coefficient of sugar and canopy temperature had a high direct effect on white sugaryield.

Rajabi et al. (2014) used multivariate analysis for yield and quality traits of sugar beet in drought stress condition and classified the genotypes into four groups among which the one group was found to be superior with respect to yield and quality. Ghasemi et al. (2010) found a genetic variation for morphological and physiological traits in sugar beet as revealed by cluster analysis. They assigned the difference between the results of cluster analysis and means comparisons to the likely unequal contribution of the measured traits to white sugaryield.

Rajabi et al. (2013) reported a high narrow-sense heritability for morphological as well as quality traits such as $\mathrm{Na}$ and extraction coefficient of sugar in sugar beet in late sowing conditions which support our results but they found low heritability values for root yield, sugar yield and white sugar yield. Niazian et al. (2012) reported the highest and lowest phenotypic variation for root yield and extraction coeff icient of sugar, respectively.

The objective of the current study was to estimate heritability and correlations among traits under drought stress condition and to identify the best genotypes and the most important traits influencing white sugar yield in sugar beet.

\section{Materials and methods:}

This study was conducted at Agricultural Research Stations of Karaj and Miandoab, Iran in 2014. The 30-year average temperature and an annual rainfall of the location were $13.5^{\circ} \mathrm{C}$ and $243 \mathrm{~mm}$, respectively and the soil of the field was clay-loam. Miandoab station is located northwest of the city at an altitude of $1314 \mathrm{~m}$. This area has the Ferric temperature regime (the average annual temperature of the soil is $8-15^{\circ} \mathrm{C}$ ) and Xeric moisture regime (semi-arid) with the soil of the field being siltyloam.

In this research, 37 sugar beet half-sib families (Table1) derived from three selection cycles in drought stress condition along with the original populations and check varieties were evaluated in a randomized complete block design with three replications. Seedbed preparation practices such as ploughing, disking and levelling were uniformly applied. Potassium and phosphorous fertilisers were applied at the time of seedbed preparation and nitrogen fertiliser was applied as topdressing. The between- and within-row spacing was 50 and $15 \mathrm{~cm}$, respectively. Each plot consisted of three rows of $8 \mathrm{~m}$ length. Cultural practices including irrigation and control of diseases and pests were applied when needed. After plant establishment (4-6-leaf stage), furrow irrigation was applied on the basis of cumulative evaporation from the class A evaporation pan. The inlet and outlet irrigation water was measured by using WSC flumes. During the growing season, some morphophysiological traits such as chlorophyll content (CC), specific leaf weight (SLW) (gr.cm-2) and water use efficiency (WUE) (Y/ET) were measured by taking samples from five fully expanded leaves per plot.

Harvest was done early November. The roots harvested were washed, weighed and used to take brie (pulp) samples. The brie samples were then immediately frozen and sent to the Sugar Beet Technology Lab of Sugar Beet Seed Institute, Karaj, Iran, for determination of root related traits such as root yield (RY) (t.ha-1), sugar content (SC) (gr sugar/10o gr beet), sodium (Na) (meq/10o gr beet), and potassium (K) (meq/10o gr beet). Sugar content (SC) (gr sugar/100 gr beet) was measured by the 
Table-1: The list of studied genotypes

\begin{tabular}{llllll}
\hline No. & Genotype & No. & Genotype & No. & Genotype \\
\hline 1 & HSF - 841 & 16 & HSF - 859 & 31 & HSF - 876 \\
2 & HSF - 842 & 17 & HSF - 860 & 32 & HSF - 877 \\
3 & HSF - 843 & 18 & HSF - 861 & 33 & HSF - 881 \\
4 & HSF - 844 & 19 & HSF - 862 & 34 & HSF - 882 \\
5 & HSF - 846 & 20 & HSF - 864 & 35 & HSF - 883 \\
6 & HSF - 847 & 21 & HSF - 865 & 36 & HSF - 884 \\
7 & HSF - 848 & 22 & HSF - 866 & 37 & HSF - 885 \\
8 & HSF - 849 & 23 & HSF - 867 & 38 & 110 \\
9 & HSF - 850 & 24 & HSF - 868 & 39 & 191 \\
10 & HSF - 851 & 25 & HSF - 869 & 40 & 31265 \\
11 & HSF - 852 & 26 & HSF - 870 & 41 & $32434-91$ \\
12 & HSF - 854 & 27 & HSF - 871 & 42 & $32926-92$ \\
13 & HSF - 855 & 28 & HSF - 872 & 43 & F - 20505 \\
14 & HSF - 856 & 29 & HSF - 873 & & \\
15 & HSF - 857 & 30 & HSF - 875 & & \\
\hline
\end{tabular}

polarimetric method, $\mathrm{Na}$ and $\mathrm{K}$ by flame photometry and $\mathrm{N}$ by blue number method. Molasses sugar (MS) (gr sugar/100 gr beet) was estimated by using the formula of Reinfeld et al. (1974). Sugar yield (SY) (t.ha-1), white sugar yield (WSY) (t.ha-1), white sugar content (WSC) (\% in beet), extraction coefficient of sugar (ECS) (\% in sugar) and alkalinity (Alk) (\% in beet) were calculated based on the following equations (Abdollahian et al., 2005):

$$
\begin{aligned}
& \text { SY }=\text { Root yield }(\mathrm{RY}) \times \mathrm{SC} \\
& \text { WSY }=\text { RY } \times \text { WSC } \\
& \text { WSC }=\text { SC }-(\text { MS }+ \text { sugar losses in factory }) \\
& \text { ECS }=(\text { WSC } / S C) \times 100
\end{aligned}
$$

Genetic parameters and narrow-sense heritability were estimated after Halluaer \& Miranda (1982) on the basis of expected mean squares of the Table of ANOVA (Table 2 ).

Table 2. Expected mean of squares.

\begin{tabular}{llll}
\hline S.O.V & $\mathrm{Df}$ & $\mathrm{MS}$ & $\mathrm{E}(\mathrm{MS})$ \\
Replication & $\mathrm{df}_{\mathrm{R}}$ & $\mathrm{MS}_{\mathrm{R}}$ & $\sigma_{\mathrm{e}}^{2}+\mathrm{g} \sigma_{\mathrm{r}}^{2}$ \\
Genotype & $\mathrm{df}_{\mathrm{G}}$ & $\mathrm{MS}_{\mathrm{G}}$ & $\sigma_{\mathrm{e}}^{2}+\mathrm{r}_{\mathrm{g}}^{2}$ \\
Error & $\mathrm{df}_{\mathrm{E}}$ & $\mathrm{MS}_{\mathrm{E}}$ & $\sigma_{\mathrm{e}}^{2}$ \\
\hline
\end{tabular}

$$
\begin{aligned}
& \text { COVH.S }=\sigma_{\mathrm{g}}^{2}=\frac{M S g-M S e}{r} \\
& \sigma^{2} \mathrm{~A}=4 \sigma_{\mathrm{g}}^{2}={ }_{4} \text { COVH.S } \\
& \mathrm{h}_{\mathrm{n}}{ }_{\mathrm{n}}=\frac{\sigma_{\mathrm{g}}^{2}}{\left(\sigma_{\mathrm{g}}^{2}+\sigma_{\mathrm{g}}^{2} \mathrm{~m} / \mathrm{r}+\sigma_{\mathrm{e}}^{2} / \mathrm{rm}\right)}
\end{aligned}
$$

Where as $h_{n}^{2}$ narrow-sense heritability, $\sigma_{\mathrm{g}}^{2}$ is genetic variance, $\sigma_{\mathrm{gm}}^{2}$ the variance of genotype by environment interaction, $\sigma_{e}^{2}$ is error variance, $r$ is the number of replications and $\mathrm{m}$ is the number of environments. Phenotypic (PCV) and genotypic (GCV) coefficient of variation was calculated according to the following equations:

$$
\mathrm{PCV}=\sigma_{p} / \bar{x} \times 100 ; \quad \mathrm{GCV}=\sigma_{g} / \bar{x} \times 100
$$

Where $\sigma_{p}$ and $\sigma_{q}$ are the phenotypic and genotypic standard deviation, respectively, and $\bar{x}$ is the grand mean of the traits. Genetic gain $(\mathrm{Gg})$ for the selection intensity of $5 \%$ was calculated by using the following equation:

$$
\mathrm{Gg}=\mathrm{K} \sigma_{A}^{2} / \sigma_{\mathrm{ph}}^{2}
$$

Where $\mathrm{K}$ is the selection differential, $\sigma_{\mathrm{p}}$ is the phenotypic standard deviation, and $\sigma_{A}^{2}$ is the additive variance. Before data analysis, normality test was done and then the analysis of variance for the traits was conducted and Duncan's multiple range test was use to separate the means. Then, combined analysis of variance was carried out for the traits over two locations in drought stress condition. The software SPSS, SAS and Excel were used for statistical analysis.

\section{Results \& Discussion :}

Analysis of variance for agronomic and morphophysiological traits (Table-3) revealed that the two locations differed significantly at $1 \%$ probability level ( $\mathrm{p}=\mathrm{o.o1}$ ) for root yield, sugar yield, white sugar yield, alkalinity, leaf chlorophyll content, water use efficiency, specif ic leaf weight and leaf succulence index. There was a significant difference among the genotypes for all of the traits except $\mathrm{K}$, white sugar yield and specific leaf weight. The presence of significant difference among the genotypes indicates the existence of genetic variation among them. Genetic variation is one of the requirements for plant breeding so that successful selection of superior genotypes from a population depends on genetic variation and without that, no progress in plant breeding is realised. In this regard, a higher genetic variation for a trait provides better opportunity for selection. On the other hand, genetic diversity provides a long-term adaptability and survival for a population. Therefore, it is highly important to create and maintain genetic variation in a plant breeding program. The interaction of genotypes by environment was only significant for $\mathrm{Na}$, alkalinity and extraction coefficient of sugar at $1 \%$ probability level. The non-significant interaction of genotypes by the environment for most of the traits indicates that the genotypes in the two locations performed similarly with respect to these traits, especially root yield, sugaryield and white sugar yield. Therefore, for most of the traits, the means of two locations were used. Bakshi et al. (2012) studied the impact of drought stress on some yield and quality traits of new improved sugar beet varieties and found significant differences among the genotypes for all of the traits studied except alpha-amino nitrogen, $\mathrm{Na}$ and molasses sugar. In a similar study, Sharifi (2014) observed signif icant differences among the sugar beet genotypes for yield and quality traits which is in accordance with our results.

Estimation of genetic parameters: the values of narrow-sense heritability for root yield, sugar content, 
Table 3. Combined analysis of variance for the traits measured in Karaj and Miandoab.

\begin{tabular}{|c|c|c|c|c|c|c|c|c|}
\hline \multirow[t]{2}{*}{ S.O.V } & \multirow[t]{2}{*}{ Df } & \multicolumn{5}{|c|}{ MS } & \multirow[b]{2}{*}{ WSC } & \multirow[b]{2}{*}{ WSY } \\
\hline & & RY & $\mathrm{SC}$ & SY & $\mathrm{Na}$ & $\mathrm{K}$ & & \\
\hline Location(L) & 1 & $58295 \cdot 1^{* *}$ & $2.94^{\mathrm{ns}}$ & $990.23^{* *}$ & $1.93^{\mathrm{ns}}$ & $13.05^{\mathrm{ns}}$ & $6.67^{\mathrm{ns}}$ & $27 \cdot 5^{* *}$ \\
\hline Error 1 & 4 & 290.3 & 9.18 & 8.36 & 0.28 & 30.6 & 20.19 & 0.35 \\
\hline Genotype (G) & 42 & $354.9^{* *}$ & $3.42^{* *}$ & $4 \cdot 50^{* *}$ & $0.12^{* *}$ & $0.81^{\text {ns }}$ & $5 \cdot 95^{* *}$ & $0.10^{\text {ns }}$ \\
\hline $\mathrm{G} \times \mathrm{L}$ & 42 & $253.16^{\mathrm{ns}}$ & $2.98^{\mathrm{ns}}$ & $3.24^{\mathrm{ns}}$ & $0.13^{* *}$ & $1.82^{* *}$ & $3.60^{\mathrm{ns}}$ & $0.10^{\text {ns }}$ \\
\hline Error 2 & 168 & 130.3 & $1.5^{2}$ & 2.41 & 0.07 & 0.58 & 2.54 & 0.08 \\
\hline
\end{tabular}

${ }^{\mathrm{ns}}$ Non-siginificant; * significant at 0.05; ${ }^{* *}$ significant at 0.01 probability level, respectively.

RY: Root yield, SC: Sugar content, SY: Sugar yield, WSC: White sugar content and WSY: White sugar yield.

Continued table 3 .

\begin{tabular}{|c|c|c|c|c|c|c|c|c|}
\hline \multirow[t]{2}{*}{ S.O.V } & \multirow[t]{2}{*}{ Df } & \multicolumn{5}{|c|}{ MS } & \multirow[b]{2}{*}{ SLW } & \multirow[b]{2}{*}{ SI } \\
\hline & & Alk & ECS & MS & $\mathrm{CC}$ & WUE & & \\
\hline Location(L) & 1 & $2443 \cdot 5^{* *}$ & $412.47^{\mathrm{ns}}$ & $0.75^{\text {ns }}$ & $6057.8^{* *}$ & $8.06^{* *}$ & $0.020^{* *}$ & $0.009^{*}$ \\
\hline Error 1 & 4 & $14 \cdot 51$ & 623.56 & 4.01 & 335.2 & 0.04 & 0.015 & 0.0003 \\
\hline Genotype (G) & 42 & $14.21^{* *}$ & $110.96^{* *}$ & $0.57^{* *}$ & $88.3^{*}$ & $0.04^{* *}$ & $0.006^{\mathrm{ns}}$ & $0.0002^{*}$ \\
\hline $\mathrm{G} \times \mathrm{L}$ & 42 & $14.91^{* *}$ & $117 \cdot 91^{* *}$ & $0.38^{\mathrm{ns}}$ & $61.9^{\text {ns }}$ & $0.02^{\mathrm{ns}}$ & $0.005^{\mathrm{ns}}$ & $0.001^{\text {ns }}$ \\
\hline Error 2 & 168 & 8.83 & 54.68 & 0.25 & 56.5 & 0.01 & 0.005 & 0.0001 \\
\hline
\end{tabular}

Alk: Alkalinity, ECS: Extraction coefficient of sugar, MS: Molasses sugar, CC: Chlorophyll content, WUE: Water use efficiency,

SLW: Specific leaf weight and SI: Succulence index.

Table 4. Estimate of genetic parameters for the traits measured in Karaj and Miandoab.

\begin{tabular}{llllllll}
\hline Parameters & RY & SC & SY & Na & K & WSC & WSY \\
Best half-sib & 75.25 & 14.24 & 9.16 & 5.14 & 7.3 & 10.44 & 5.85 \\
Inferior half-sib & 38.16 & 11.3 & 4.94 & 3.04 & 6.08 & 6.46 & 3.43 \\
Range & 20.72 & 1.58 & 2.27 & 0.86 & 0.56 & 2.17 & 1.35 \\
COV $_{\mathrm{HS}}=\sigma_{\mathrm{g}}^{2}$ & 31.53 & 0.63 & 0.42 & 0.016 & 0.076 & 1.31 & 0.006 \\
$\sigma_{\mathrm{A}}^{2}=4 \sigma_{\mathrm{g}}^{2}$ & 126.13 & 2.53 & 1.46 & 0.06 & 0.3 & 4.54 & 0.026 \\
$\mathrm{~h}_{\mathrm{n}}^{2}$ & 60.61 & 87.1 & 47.9 & 80 & 60.52 & 89.88 & 64 \\
PCV $(\%)$ & 26.34 & 13.36 & 27.13 & 4.3 & 20.87 & 26.8 & 4.52 \\
$\mathrm{GCV}(\%)$ & 23.75 & 12.47 & 25.15 & 3.84 & 16.23 & 25.41 & 3.62 \\
$\mathrm{Gg}$ & 18.21 & 3.06 & 1.87 & 0.28 & 0.71 & 2.24 & 0.2 \\
LSD5\% & 4.41 & 0.47 & 0.57 & 0.1 & 0.29 & 0.61 & 0.1 \\
\hline
\end{tabular}

RY: Root yield, SC: Sugar content, SY: Sugar yield, WSC: White sugar content and WSY: White sugar yield

Continued table 4 .

\begin{tabular}{|c|c|c|c|c|c|c|c|}
\hline Parameters & Alk & ECS & MS & $\mathrm{CC}$ & WUE & SLW & SI \\
\hline Best half-sib & 9.83 & 73.03 & 4.22 & 53.25 & 0.008 & 0.0098 & 0.11 \\
\hline Inferior half-sib & 2.9 & 55.85 & 3.19 & 26.71 & 0.0047 & 0.006 & 0.034 \\
\hline Range & 4.46 & 8.57 & 0.44 & 18.5 & 0.0016 & 0.0034 & 0.083 \\
\hline $\mathrm{COV}_{\mathrm{HS}}=\sigma_{\mathrm{g}}^{2}$ & 1.79 & 18.76 & 0.106 & 10.6 & 0.01 & 0.0003 & 0.0003 \\
\hline$\sigma_{\mathrm{A}}^{2}=4 \sigma_{\mathrm{g}}^{2}$ & $7 \cdot 17$ & 75.04 & 0.42 & 4.42 & 0.04 & 0.001 & 0.001 \\
\hline$h_{n}^{2}$ & 78.38 & 83.91 & 89.04 & 81.11 & 74.11 & 61.15 & 59.25 \\
\hline PCV (\%) & 56.75 & $14 \cdot 5^{8}$ & 18.36 & $13 \cdot 58$ & 32.72 & 58.92 & 32.6 \\
\hline GCV (\%) & 50.24 & 13.35 & $17 \cdot 32$ & 12.23 & 31.74 & 46.22 & 25.1 \\
\hline $\mathrm{Gg}$ & 3.02 & 9.45 & 0.69 & 7.22 & 0.2 & 0.04 & 0.015 \\
\hline $\mathrm{LSD}_{5} \%$ & 1.14 & 2.85 & 2.9 & 2.97 & 0.0038 & 0.027 & 0.0038 \\
\hline
\end{tabular}

ALK:Alkalinity, ECS: Extraction coefficient of sugar, MS: Molasses sugar, CC: Chlorophyll content, WUE: Water use eff iciency, SLW: Specif ic leaf weight and SI: Succulence index. 
white sugar content, sugar yield, extraction coefficient of sugar, white sugar yield and chlorophyll content were estimated to be 6o.61, 87.10, 90.88, 47.90, 83.91, 64.0o and $81.11 \%$, respectively (Table-4). Except sugar yield which had a heritability lower than average, the values for the other traits were higher than the average. As narrow-sense heritability is the the ratio of additive variance to phenotypic variance, it can be stated that the abovementioned traits are mainly governed by additive genetic variance. The highest and lowest phenotypic and genotypic variation was observed in alcalinity and specif ic leaf weight, respectively. Also, root yield and sugar yield displayed a higher phenotypic and genotypic variation than the other traits. Therefore, the highest genetic gain was found for root yield, extraction coefficient of sugar, chlorophyll content and sugar content, respectively (Table-4). It has been shown that without genetic gain, heritability values will not have practical importance in phenotype-based selection (Ehdaie \& Wains, 1997). Thus, in plant breeding programs for concurrent selection, the genetic gain has to be considered along with the heritability. As higher heritability values, as well as optimum quantities of genetic gain, were found for root yield, extraction coefficient of sugar, chlorophyll content and sugar content, selection of genotypes based on these traits will likely be effective in achieving genotypes with high root and sugar yields. MacLachlan (1972) estimated the genetic variance and mode of gene action for root yield, sugar content and components of sugar beet quality and reported that non-additive gene effects had higher importance for sugar yield whereas additive gene effects were more important for sugar content and quality components. Fathi et al. (2007) reported that root yield, sugar yield and white sugar yield were more affected by additive effects. Rajabi et al. (2013) found higher narrowsense heritability values for morphological traits as well as root quality traits such as $\mathrm{Na}$ and extraction coeff icient of sugar which is in line with our results, whereas they reported rather low values for root yield, sugar yield and white sugar yield which are different from our findings. It is necessary to emphasise that additive and dominance effects vary depending on the type of breeding materials, the mating design used and experimental conditions. Therefore, precise knowledge of the genetic structure of yield-related traits and their heritability facilitates selection and success of breeding programs. Niazian et al. (2012) evaluated sugar beet genotypes by using the diallel method and found the highest broad-sense heritability for root length with the highest and lowest phenotypic variation for root yield and extraction coeff icient of sugar, respectively.

Correlations among traits and path analysis: according to the results of correlation analysis (Table-5), white sugar yield had positive signif icant correlation with

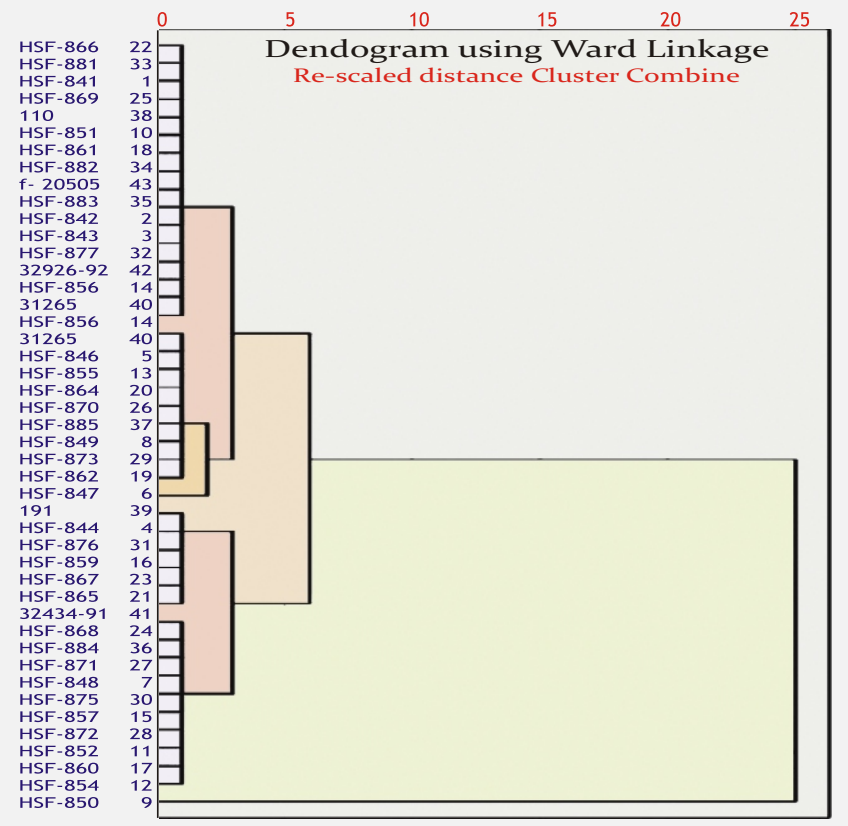

Figure-1: Dendrogram of studied genotypes over the two location based on assayed traits.

root yield, sugar content, sugar yield, white sugar content, extraction coeff icient of sugar, chlorophyll content, water use efficiency and specific leaf weight, and negative significant correlation with $\mathrm{Na}$ (Sodium), K (Potassium), alkalinity and molasses sugar. As these traits have an acceptable level of heritability, genetic variation and genetic gain, they could be used to select genotypes with high root yield, sugar content, sugar yield, white sugar content, extraction coefficient of sugar and chlorophyll content, and low $\mathrm{Na}, \mathrm{K}$, alkalinity and molasses sugar. Ouda Sohier (2005), reported that root yield and sugar content are the most important traits affecting sugar yield which is in line with our results. As simple correlation coefficients do not provide clear information on the nature of cause and effect relationship among the traits of interest, decomposition of the correlation coefficients into direct and indirect effects strengths the degree of impact of independent variables on dependent variable (Ali et al., 2003). Therefore, to identify the traits influencing white sugar yield, stepwise regression analysis was used across the two locations (Table-6). Results showed that sugar yield, molasses sugar and white sugar content totally explaining $99 \%$ of the variation of white sugar yield were found to be the most effective traits and thus they were used for path analysis (Table-7). Results of path analysis indicated that sugar yield and sugar content had direct positive, significant effect and molasses sugar had a negative signif icant effect on white sugar yield. Also, each of the three remaining traits had a positive significant effect on white sugar yield via the other two traits. Baradaran-Firouzabadi (2002) found the highest direct effect on sugar content, molasses sugar, sugar yield 
and root diameter in normal condition and for sugar content, molasses sugar and sugar yield in drought stress condition.

Table-5: Correlation coeff icients among the traits combined over the two locations.

\begin{tabular}{|c|c|c|c|c|c|c|c|}
\hline Trait & 1 & 2 & 3 & 4 & 5 & 6 & 7 \\
\hline$\overline{1}$ & 1 & & & & & & \\
\hline 2 & $-0.08^{\text {ns }}$ & 1 & & & & & \\
\hline 3 & $0.96^{* *}$ & $0.17^{* *}$ & 1 & & & & \\
\hline 4 & $-0.08^{\text {ns }}$ & $-0.75^{* *}$ & $-0.26^{* *}$ & 1 & & & \\
\hline 5 & $-0.04^{\mathrm{ns}}$ & $-0.08^{\mathrm{ns}}$ & $-0.01^{\mathrm{ns}}$ & $0.20^{* *}$ & 1 & & \\
\hline 6 & $-0.10^{\mathrm{ns}}$ & $0.90^{* *}$ & $0.13^{* *}$ & $-0.83^{* *}$ & $-0.29^{* *}$ & 1 & \\
\hline 7 & $0.86^{* *}$ & $0.37^{* *}$ & $0.96^{* *}$ & $-0.49^{* *}$ & $-0.15^{*}$ & $0.37^{* *}$ & 1 \\
\hline 8 & $-0.04^{\mathrm{ns}}$ & $0.84^{* *}$ & $0.16^{* *}$ & $-0.86^{* *}$ & $-0.42^{* *}$ & $0.94^{* *}$ & $0.62^{* *}$ \\
\hline 9 & $-0.54^{* *}$ & $-0.30^{\mathrm{ns}}$ & $-0.29^{* *}$ & $-0.35^{* *}$ & $-0.24^{* *}$ & $-0.60^{* *}$ & $-0.33^{* *}$ \\
\hline 10 & $0.12^{*}$ & $-0.75^{* *}$ & $-0.01^{\mathrm{ns}}$ & $-0.76^{* *}$ & $0.70^{* *}$ & $-0.77^{\mathrm{ns}}$ & -0.86 \\
\hline 11 & $-0.66^{* *}$ & $-0.04^{\text {ns }}$ & $0.66^{* *}$ & $0.25^{* *}$ & $0.15^{*}$ & $-0.05^{\text {ns }}$ & 0.12 * \\
\hline 12 & $0.07^{\text {ns }}$ & $-0.10^{\mathrm{ns}}$ & $0.06^{\text {ns }}$ & 0.12 * & $0.01^{\text {ns }}$ & $-0.11^{\mathrm{ns}}$ & $-0.10^{\mathrm{ns}}$ \\
\hline 13 & $0.63^{* *}$ & $-0.53^{* *}$ & $0.39^{* *}$ & $0.14^{\mathrm{ns}}$ & $0.10^{\text {ns }}$ & $0.37^{* *}$ & $0.84^{* *}$ \\
\hline 14 & $0.60^{* *}$ & $0.44^{* *}$ & $0.30^{*}$ & $0.17^{\text {ns }}$ & $0.16^{\text {ns }}$ & $0.36^{* *}$ & $0.33^{* *}$ \\
\hline Trait & 8 & 9 & 10 & 11 & 12 & 13 & 14 \\
\hline 8 & 1 & & & & & & \\
\hline 9 & $0.39^{* *}$ & 1 & & & & & \\
\hline 10 & $0.17^{* *}$ & $0.25^{* *}$ & 1 & & & & \\
\hline 11 & $0.63^{* *}$ & $-0.64^{* *}$ & $0.05 \mathrm{~ns}$ & 1 & & & \\
\hline 12 & $0.01 \mathrm{~ns}$ & $0.03 \mathrm{~ns}$ & $0.10 \mathrm{~ns}$ & $0.01 \mathrm{~ns}$ & 1 & & \\
\hline 13 & $-0.20 \mathrm{~ns}$ & $-0.26 \mathrm{~ns}$ & $-0.10 \mathrm{~ns}$ & $-0.23 n s$ & $0.10 \mathrm{~ns}$ & 1 & \\
\hline 14 & 0.17 ns & $0.16 \mathrm{~ns}$ & 0.14 ns & $0.14 \mathrm{~ns}$ & $0.15 \mathrm{~ns}$ & $0.13 \mathrm{~ns}$ & 1 \\
\hline
\end{tabular}

${ }^{\mathrm{ns}}$ Non-siginificant; * signif icant at $0.05 ;{ }^{* *}$ signif icant at 0.01 probability level, respectively.

1: Root yield, 2: Sugar content, 3: Sugar yield, 4: Na, 5: K, 6: White sugar content, 7: White sugar yield, 8: Alkalinity, 9: Extraction coefficient of sugar, 10: Molasses sugar, 11: Chlorophyll content, 12: Water use efficiency, 13: Specific leaf weight and 14: Succulence index.

Table-6: Stepwise regression for white sugar yield as dependent variable and other traits as independent variables in Karaj \& Miandoab.

\begin{tabular}{llll}
\hline & 1 & 2 & 3 \\
\hline Constant & -0.11 & 2.5 & 0.43 \\
White sugar yield & 0.67 & 0.66 & 0.65 \\
Molasses sugar & - & $0.69-$ & $0.52^{-}$ \\
Sugar content & - & - & 0.12 \\
R2 & 0.91 & 0.98 & 0.99 \\
\hline
\end{tabular}

Table-7: Path analysis for white sugar yield as dependent variable and other traits as independent variables in Karaj \& Miandoab.

Direct effect Indirect effect

\begin{tabular}{lllll} 
& & 1 & 2 & 3 \\
\hline 1-Sugar yield $^{-}$ & $0.94^{* *}$ & 1 & 0.172 & 0.04 \\
2-Molasses sugar & $-0.20^{* *}$ & 0.8 & - & 0.06 \\
3-White sugar content & $0.11^{* *}$ & 0.34 & 0.11 & - \\
\hline
\end{tabular}

Cluster analysis: as the genotypes differ greatly with respect to the traits measured, it doesn't seem to be correct to judge just on the basis of one or a few morphological traits. Therefore, in addition to correlation analysis, various statistical methods are used to select the best genotypes. One of these methods is cluster analysis. As shown in fig.-1, cut-off at different positions of dendrogram derived from cluster analysis resulted in 3, 4 and 5 groups. To confirm the differences among the groups, multivariate analysis based on randomised complete block design was conducted for the traits measured. on the basis of Wilks Lambda statistic, the highest $\mathrm{F}$ value and hence the highest between-group to within-group variance ratio was observed in three-group condition. On this basis, 43 genotypes were divided into three groups. Analysis of variance for the three groups showed that the groups differed significantly in sugar content, $\mathrm{Na}$, white sugar content, extraction coeff icient of sugar, white sugaryield and succulence index (Table-8). To precisely determine the differences among the clusters for each trait, means of traits of the clusters was compared using LSD method. When the mean of a trait in a cluster is higher than the grand mean of that trait, it means that the genotypes of the cluster will have a higher value for that trait. Combined over the two locations, the first cluster contained the genotypes $22,33,1,25,38,10,18,34,43,35$, 2, $3,32,42,14,40,5,13,13,20,26,37,8,29,19,6$ and 39. The genotypes of this cluster were higher than the grand mean of all clusters with respect to sugar content, white sugar content, white sugar yield, extraction coefficient of sugar and leaf succulence index, and lower than the grand mean of all clusters for $\mathrm{Na}$ and chlorophyll content (Table-8). Therefore, as these genotypes had higher sugar yield than the other two groups and also their sugar content, white sugar content, white sugar yield, extraction coeff icient of sugar and leaf succulence index were higher, selection of these genotypes could result in the development of hybrids with higher yield and quality in future. The second cluster included the genotypes $4,31,16,23,21,41,24,36,27,7,30$, $15,28,11,17$ and 12 . Genotypes of this cluster were higher than the mean of all clusters for $\mathrm{Na}$ and lower than the mean of clusters for sugar content, $\mathrm{Na}$, white sugar content and extraction coefficient of sugar (Table-8). Consisted of only one genotype (genotype 9), cluster 3 had higher sugar content, white sugar content and extraction coeff icient of sugar than the mean of all clusters, and lower $\mathrm{Na}$ and leaf area than the mean of all clusters (Table-8). Rajabi et al. (2014), classified sugar beet genotypes into four groups with the first group containing the genotypes 25,20 and 3 being superior with respect to yield and quality. While clustering sugar beet genotypes, Ghasemi et al. (2010) found a different grouping so that the genotypes with higher similarity for the traits studied were grouped together. Results of the current study showed that the genotypes differed significantly for all of the traits studied which indicates the presence of genetic variation for selection of desirable genotypes. The genotype by environment interaction was not significant for white sugar yield and its related traits. In other words, although the two locations were significantly different for most of 
Table 8. Analysis of variance and means comparisons of groups for the traits measured over the two locations (Karaj and Miandoab).

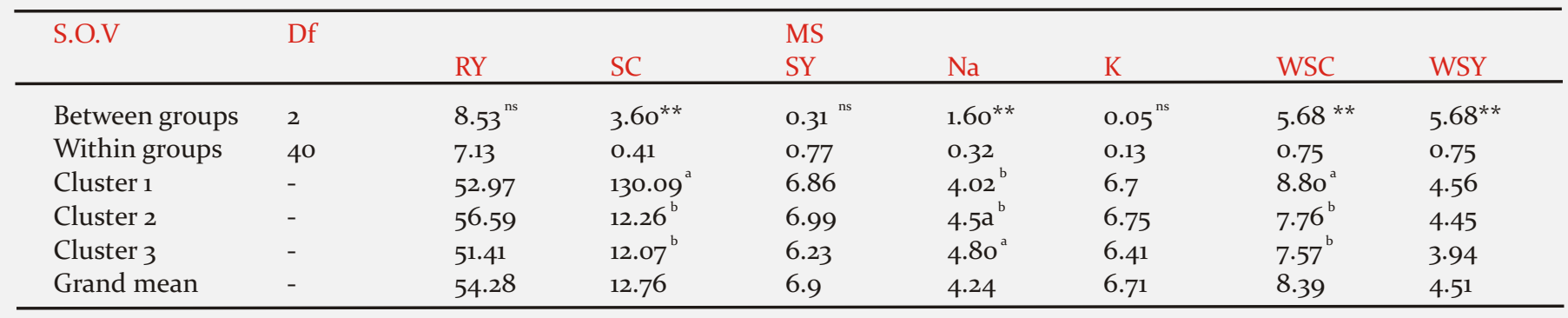

${ }^{\text {ns }}$ Non-siginificant; *significant at 0.05; ** significant at 0.01 probability level, respectively. Also different letters indicating significant difference, RY: Root yield, SC: Sugar content, SY: Sugar yield, WSC: White sugar content and WSY: White sugar yield.

Continued table 8 .

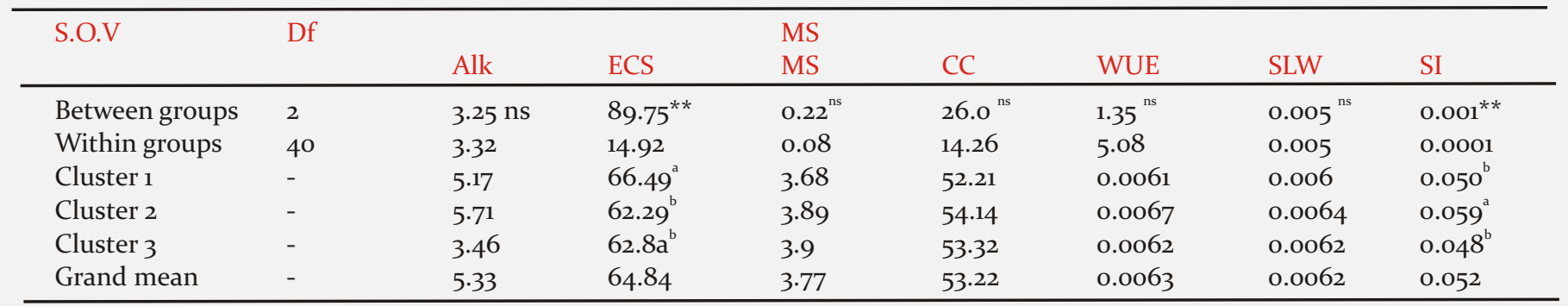

Alk: Alkalinity, ECS: Extraction coefficient of sugar, MS: Molasses sugar, CC: Chlorophyll content, WUE: Water use eff iciency, SLW: Specific leaf weight and SI: Succulence index.

the traits, the genotypes reacted similarly with respect to yield. The heritability estimates for root yield, sugar content, white sugar content, extraction coefficient of sugar, white sugar yield and chlorophyll content was found to be mid-to-high. Thus, the non-significant difference between the two environments (locations) could be attributed to the higher heritability of the traits mentioned; because the higher the heritability of a trait, the lower the trait is affected by environmental factors. Due to higher heritability and genetic gain observed for root yield, extraction coefficient of sugar, chlorophyll content and sugar content and also positive significant correlations among these traits, they could be used to select genotypes with high yield and quality. On this basis, genotypes of the first cluster (genotypes 22, 33, 1, 25, 38, 10, $18,34,43,35,2,3,32,42,14,40,5,13,13,20,26,37,8,29,19,6$ and 39) which were higher than the grand mean of the all clusters with respect to sugar content, white sugar content, white sugar yield, extraction coefficient of sugar and leaf succulence index, and lower than the grand mean of the all clusters for $\mathrm{Na}$ and chlorophyll content, could be recommended for subsequent development of the hybrids in future.

\section{Acknowledgements:}

The authors gratefully acknowledge the Islamic Azad University, Science \& Research Branch, Tehran, Iran and especially Sugar BeetSeed Institute, Karaj, Iran for financial support, lab facilities and their help in field experiments.

\section{References:}

Abdollahian, N.M., Radaei-al-Amoli, Z., Akbari, Gh.A. \& SadatNuri, S.A. (2011): Effect of severe water stress on morphological, quantitative and qualitative characteristics of 20 sugar beet genotypes. Iran. J. Field Crop Sci., 42(3): 453464.

Agrama, H.A.S. (1996): Sequential path analysis of grain yield and its components in maize. Plant Breeding, 115:343-346.

Ali, N., Javidfar, F., Yazdi, J.E. \& Mirza, M.Y. (2003): Relationship among yield components and selection criteria for yield improvement in winter rapeseed (Brassica napus L.). Pak. J. Bot., 35:167-174.

Baradaran-Firouzabadi, M. (2002): Study of relations of morphological and physiological traits of sugar beet cultivars with drought stress. MSc, University of Tabriz, Tabriz, Iran.

Bakhshi K.G., Javadi, S., Mehdikhani, P. \& Tahmasebi, D. (2011): Investigation of drought stress effects on some quantity and quality characteristics of new eugenics sugar beet genotypes. New Cell. Mol. Biotech. J., 1(3):65-74.

Board, J.E., Kang, M.S. \& Harville, B.G. (1997): Path analysis to identify indirect selection criteria for yield of late- planted soybean. Crop Sci, 37: 879-884.

Ehdaie B. \& Wains, J.G. (1997): Genetic analysis of carbon isotope discrimination and agronomic characters in a bread wheat cross. Theor. Appl. Genet., 88(8):1023-1028

Fathi, M.R., Mesbah, M., Ranji, Z., Vazan, S. \& Farokhi, E. (2007): Study of general and specif ic combining ability of sugar beet diploid pollinators. J. Sugar Beet, 23(2): 151-162.

Fotouhi, K., Mesbah, M., Sadeghian, S.Y. \& Ranji, Z. (2010): Path analysis under normal and salt stress conditions in sugar beet 
RESEARCH ARTICLE

germplasm.J.Sugar Beet, 26(1): 1-14.

Ghasemi, H., Mohammadian, R, Noushad, H. \& Danaei, M. (2010): Study of effects of some morphological and physiological traits on white sugar yield of six sugar beet monogerm varieties. J. Plant Ecol., 6(23): 80-67.

Maclachlan, J.B. (1972): Estimation of genetic parameters in a population of monogerm sugar beet (Beta vulgaris L.). 1. sibanalysis of mother-line progenies. Irish J. Agricul. Res., 11:327338.

Moghadam, M., Mohammadi S.A. \& Sarbarzeh, A.M. (1994): Introduction to multivariate statistical methods. Pishtazan Elm Tabriz Press, Tabriz, Iran.

Mohammadi, S.A. \& Prasanna, B.M. (2003): Analysis of genetic diversity in crop plants- Salient statistical tools and considerations. CropSci, 43: 1234-1248.

Niazian, M., Amiri, R., Mortazavi, S.M., Rajabi, A. \& Orazizadeh, M.R. (2012): Analysis of Resistance to Cercospora Leaf Spot and Bolting in Sugar Beet as Winter Crop Using Griffing's Diallel Method and GGE Biplot. J. Sugar Beet Res., 49(3):103123.

Ober, E., Bloa, M.L., Clark, C.J.A., Royal, A., Jaggard, K.W. \& Pidgeon, J.D. (2005): Evaluation of physiological traits as indirect selection criteria for drought tolerance in sugar beet. Field Crops Research, 91:231-249.
Ambient Science, 2016: Vol. 03(Sp2); 22-29 DOI:10.21276/ambi.2016.03.sp2.ra02

Ouda Sohier, M.M. (2005): Yield and quality of sugar beet as affected by planting density and nitrogen fertilizer levels in the newly reclaimed soil. Sugar Crops Research Institute, Agricultural Research Center, Giza, Egypt.

Pidgeon, J.D., Ober, E., Qi, A., Clark, C.J.A., Royal, A. \& Jaggard, K.W. (2006): Using multi-environment sugar beet variety trials to screen for drought tolerance. Field Crop Res., 95(2-3): 268-279.

Rajabi, A., Pirnia, P., Amiri, R., Ebrahimi, M. \& Aghaeizadeh, M. (2013): Evaluation of heritability and identif ication of suitable hybrids for late sowing in sugar beet. L. Sugar Beet, 29(2): 163174 .

Rajabi A., Vahidi H, Haj Seyed Hadi M.R. \& Fathollah Taleghani D. (2013): Study on drought tolerance and interrelationships among some agronomic and morphophysiological traits in sugar beet lines. Int. J. Agricul. Crop Sci., 5(7): 761-768.

Rajabi, A., Ghafari, E., Izadi Darbandi, A., Rouzbeh, F. \& Amiri, R. (2014): Multivariate analysis for agronomic traits and quality of sugar beet under drought stress condition. 13rd Iranian Congress of Agronomy and Crop Breeding Sciences. Karaj, Iran: Seed and Plant Improvement Institute, pp. 35-43.

Sharifi, M. (2014): Correlation and path analysis of white sugar yield with some traits under irrigation regimes in sugar beet genotypes. Plant Ecophysiol., 6(17): 74-88. 